\title{
Histological studies on the effect of calabash chalk on the cerebellum of gestating Wistar rats
}

\begin{abstract}
Calabash chalk (CC) is consumed mostly by pregnant women in the tropics to reduce salivation and by some other persons for pleasure. The aim of this study was to examine the effects of $\mathrm{CC}$ on the cerebellum of gestating wistar rats. Thirty (30) female and ten (10) male rats weighing $150-230 \mathrm{~g}$ were used for this study. Following vaginal smear, they were mated at proestrous with the males. The day after mating was designated as day 0 of gestation. The pregnant rats were randomly divided into five groups (Control, All trimester, 1st trimester, 2nd trimester and 3rd trimester) of six each and were given $0.5 \mathrm{ml}$ aqueous solution of CC containing $40 \mathrm{mg} / \mathrm{ml}$ for differentdays during their gestation period except the control group which were given $0.5 \mathrm{ml}$ of distilled water. The all trimester group were given the aqueous solution throughout their gestation period, 1st trimester 1-6days, 2nd trimester 7-12days and 3rd trimester 13-18days. On gestational day 20, the rats in all the groups were sacrificed, their cerebellum excised and fixed in $10 \%$ formol calcium and were routinely processed for histological analysis. There were no significant differences $(\mathrm{P}<0.05)$ that existed in the body weight between control and experimental groups. Histological analysis of the maternal cerebellum using Haematoxylin and eosin, Cresyl Fast Violet and Feulgen staining techniques showed changes in the cytoarchitecture of the cerebellar layers and hyperplasia of the granule cells in the experimental groups.
\end{abstract}

$\mathrm{CC}$ causes histomorphological and cellular density change in the cerebellum of gestating wistar rats which can lead to cerebellar dysfunction such as inability to maintain equilibrium or clumsy movement.

Keywords: calabash chalk, cerebellum, haematoxylin and eosin, cresyl fast violet and feulgen
Volume 5 Issue I - 2018

\author{
Godson Kelechi Peace,' Enaibe Bernard \\ Ufuoma,' Ekezie Jervas ${ }^{2}$ \\ 'Department of Anatomy, University of Ilorin, Nigeria \\ ${ }^{2}$ Department of Anatomy, Federal University of Technology, \\ Nigeria \\ Correspondence: Ekezie, Jervas Department of Anatomy, \\ School of Basic Medical Sciences Federal University of \\ Technology, PMB I 526 Owerri, Nigeria, Tel +234 8065430037 , \\ Email ekeziejervas@gmail.com
}

Received: March 26, 2017 | Published: February 09, 2018
Abbreviations: CC, calabash chalk; ALL TRIM, all trimester; 1ST TRIM, first trimester; 2ND TRIM, second trimester; 3RD TRIM, third trimester; $\mathrm{Al}_{2} \mathrm{Si}_{2} \mathrm{O}_{5} \mathrm{OH}_{4,10}$ aluminum silicate hydroxide; $\mathrm{CFV}$, cresyl fast violet

\section{Introduction}

The practice of eating soil, clay, or chalk, a form of pica called Geophagy ${ }^{1}$ occurs deliberately or accidental. ${ }^{2}$ It is seen in most parts of the world ${ }^{3}$ but more extensive in the tropics. ${ }^{4}$ Reports show that it occurs with animals, as well as humans, in both sexes, and in all races ${ }^{5}$ in UK it is associated with immigrants from South Asia ${ }^{6-8}$ and West African. ${ }^{9,10}$

Geophagy, although often seen in rural or preindustrial settings among children and pregnant women ${ }^{11}$ is not limited to any particular age or time. ${ }^{12}$ Clay consumption has been reported to be associated with pregnancy, and some women eat clay to eliminate nausea. ${ }^{13}$ Report says that this process may also result in the absorption of dangerous toxins and eggs of parasites that may have been passed in animal faeces. ${ }^{14}$ Anaemia, which is a deficiency of red blood cell and haemoglobin (oxygen-carrying pigment in the blood), as well as Ascaris lumbricoides infection, are some of the other factors associated with geophagy. ${ }^{14}$

CC (calabash clay, Calabar stones) is also called poto, la craie or Argile by the Francophones; Nzu by the Igbos, and Ndom by the Efiks/Ibibios of Nigeria. It is also referred to as Mabele by the Lingala of Congo. Although commercially available in blocks/pellets, it is also sold in powdered form. ${ }^{15} \mathrm{CC}$ is made up of aluminum silicate hydroxide, which is a well-known member of the kaolin clay group, with the formula: $\mathrm{Al}_{2} \mathrm{Si}_{2} \mathrm{O}_{5} \mathrm{OH}_{4}{ }^{10}$ Other substances which could be poisonous to the body have also been reported to be present in clay. ${ }^{10}$ These include metals, metalloids, and persistent organic pollutants. ${ }^{10}$ The metals include iron, aluminium, potassium, titanium, barium, chromium, zinc, manganese, nickel, rubidium, copper, and tin with the metalloids being lead the mean concentration of approximately $40 \mathrm{mg} / \mathrm{kg}$ and arsenic. ${ }^{10,15-17}$

Various organic pollutants have been reported to be present in clay/CC. Such organic pollutants include alpha lindane, endrin, endosulphan II, and P, PI-dichloro diphenyl dichloroethane (DDD). ${ }^{10}$ The European Union recommends that the highest concentration of lead permitted in specific foods should not exceed $1 \mathrm{mg} / \mathrm{kg}$ (Commission Regulation, 2001) ${ }^{18}$ However, lead levels in CC have been reported in the range of $10-50 \mathrm{mg} / \mathrm{kg} .{ }^{10}$

Due to the high consumption of calabash chalk by pregnant and breastfeeding women as remedy for morning sickness, this study investigated the possible effects of calabash chalk on the cerebellum of gestating wistar rats.

\section{Materials and methods}

Thirty (30) female wistar rats and ten (10) male rats weighing $150-220 \mathrm{~g}$ and $190-230 \mathrm{~g}$ respectively were used for the experiment. Blocks of salted calabash chalk were grounded into powder using a manually operated grinder. A $40 \mathrm{~g}$ sample of the powder was dissolved in $1000 \mathrm{ml}$ of distilled water. 
The solution was left for 24 hours and was filtered. The filtrate was stored in a plastic container and kept in the refrigerator. Vaginal smear test was carried out prior to mating; this was done to know the phase of estrous cycle of female rats before introducing the male rats. ${ }^{19}$ The following day was taken as day zero $(0)$ of pregnancy. ${ }^{19}$

The pregnant rats were randomly divided into five groups of six each and were given $0.5 \mathrm{ml}$ aqueous solution of CC containing $40 \mathrm{mg} /$ $\mathrm{ml}$ for different days during their gestation period except the control group which were given $0.5 \mathrm{ml}$ of distilled water. The all trimester group were given the aqueous solution throughout their gestation period, 1st trimester day 1-6, 2nd trimester day 7-12 and 3rd trimester day 13-18. On gestational day 20, the rats in all the groups were weighed and sacrificed by cervical dislocation; the maternal brains were then excised and weighed. Tissues for histological studies were fixed in $10 \%$ formol calcium and processed using Hematoxylin and Eosin, Cresyl fast violet (CFV) for demonstration of Nissl substance and Feulgen stain for demonstration of DNA.

\section{Data analysis}

Data obtained were analyzed using ANOVA t-test (LSD) and the data presented as Mean \pm standard error of mean (SEM), with confidence interval at $95 \%$.

\section{Results}

During gestation there were no significant difference $(\mathrm{P}<0.05)$ that existed in the maternal body weight, maternal cerebellar weight between the control and the experimental groups. However, there were weekly body weight gains among all the groups as the experimental groups were exposed to the same $0.5 \mathrm{ml}$ aqueous solution of $\mathrm{CC}$.

Histological observation using CFV and Feulgen stain showed destruction of normal cytoarchitecture of the maternal cerebelli and hyperplasia of the granule cells as well as decreased staining intensity for Nissl cells and the nuclei, compared with animals in the control groups (Figure 1).

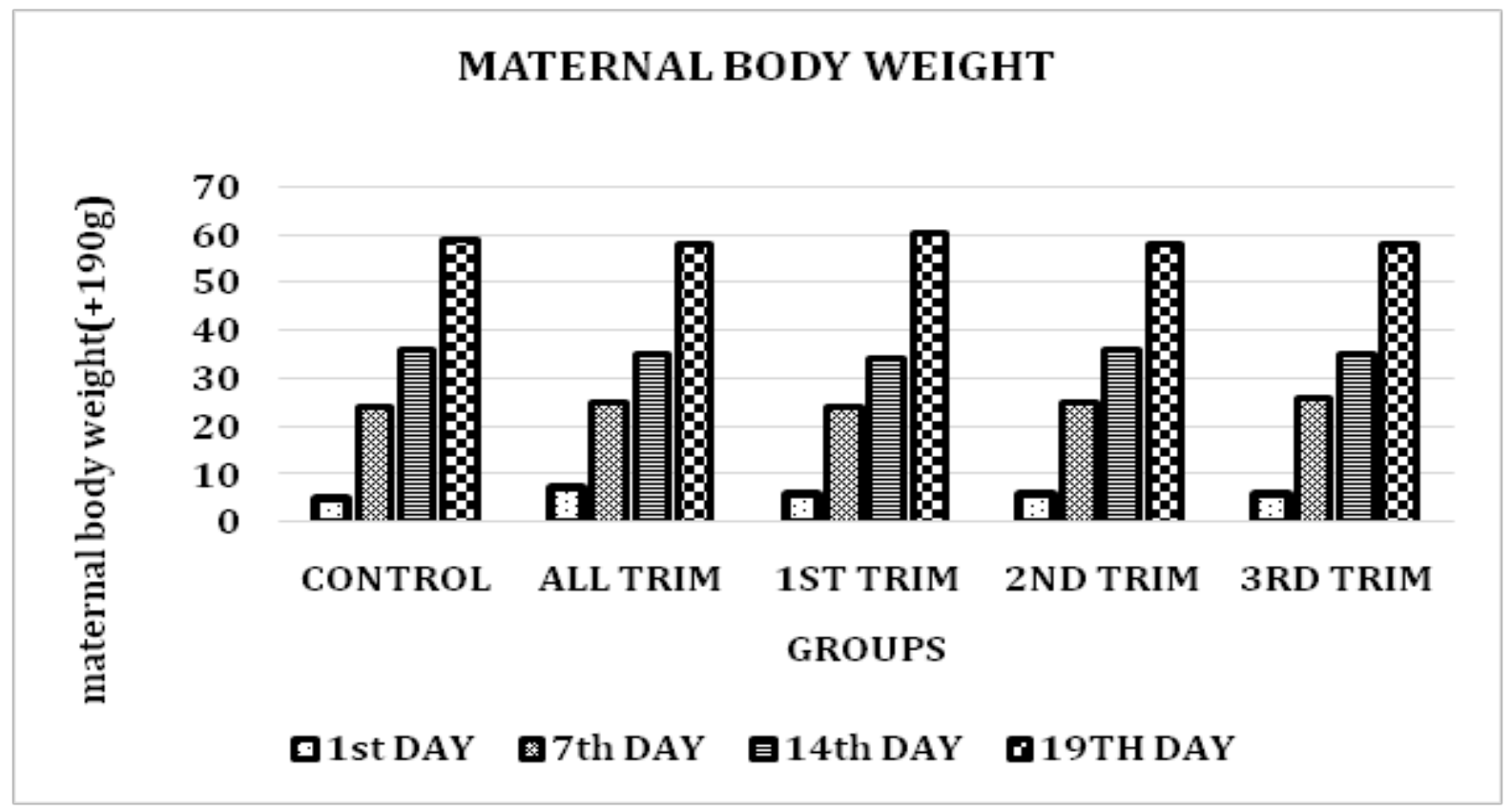

Figure I Bar chart showing maternal body weight of wistar rats during gestation.

ALL TRIM, all trimester; IST TRIM, first trimester; 2ND TRIM, second trimester; 3RD TRIM, trimester There was no significant difference between the control and the treated groups $(\mathrm{P}<0.05)$.

\section{Histological observations}

In Group A, the molecular layer was distinct and the granular layer is densely packed with small dendritic cells. The cells that form the Purkinje layer are visible. The demarcation between the molecular and granular layer can be seen. The molecular and granular layer of Groups B, C and D are less stained, the cells that form the Purkinje layer are not visible. In Group E, the demarcation between the molecular and granular layer can be seen showing the cerebellar layers (Figures 2-4).

The granule cells in Group A are deeply stained. Group B shows deeply stained and large granular cells. Group $\mathrm{C}$ shows less stained and destructive cells. Group D and E shows deeply stained and fewer cells when compared with control (Figure 5).

Group A: showed distinct cerebellar layers. The molecular layer appeared more distinct with a visible higher distribution of cells; the granular layer becomes denser while the purkinje layers are also visible. The demarcation between the molecular and granular layer are visible. The Purkinje layers are not visible in the treated groups. There was apparent distortion in the regular arrangement of the treated group compared to control. The granular layers are not visible in group C (Figure 6).

Group A showed deeply stained granular cells. Group C, D and E showed hyperplastic granular cells while Group B showed vacuolation of the neurons (Figure 7). 

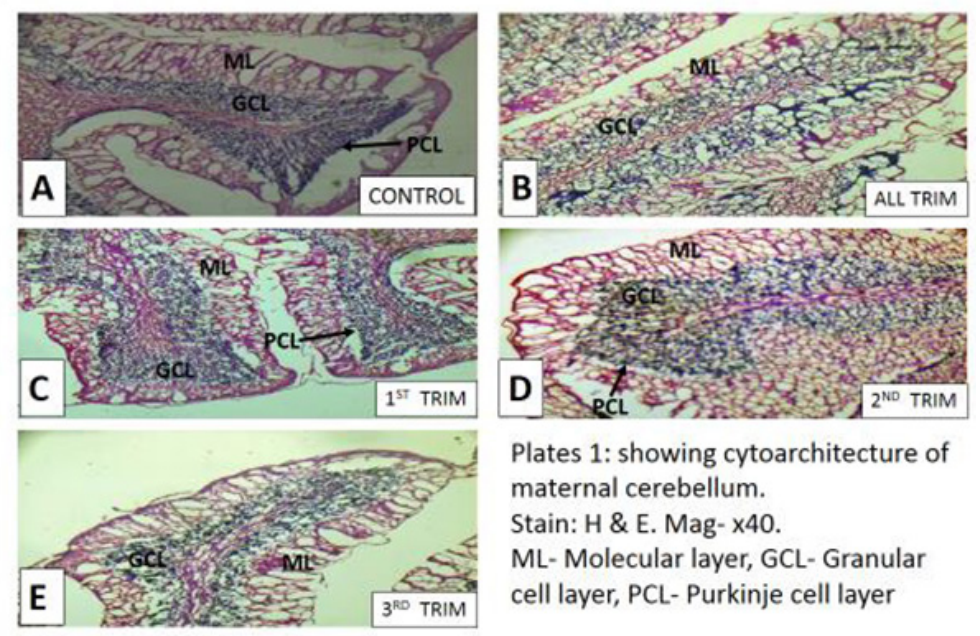

Plates 1: showing cytoarchitecture of maternal cerebellum.

Stain: H \& E. Mag- $x 40$.

ML- Molecular layer, GCL- Granular cell layer, PCL- Purkinje cell layer

Figure 2 Showing cytoarchitecture of maternal cerebellum. Stain: H\& E. Mag- $\times 40$.

$\mathrm{ML}$, molecular layer; $\mathrm{GCL}$, granular cell layer; $\mathrm{PCL}$, purkinje cell layer
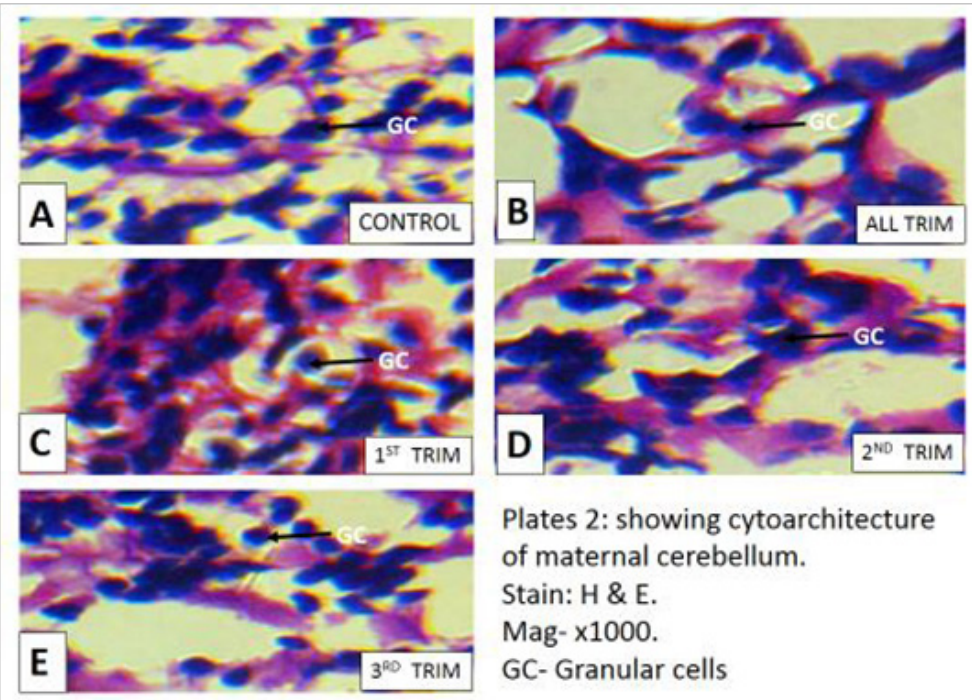

Plates 2: showing cytoarchitecture of maternal cerebellum.

Stain: $H$ \& E.

Mag- $x 1000$.

GC- Granular cells

Figure 3 Showing cytoarchitecture of maternal cerebellum. Stain, H\& E. Mag- $\times 1000$.

GC, granular cell
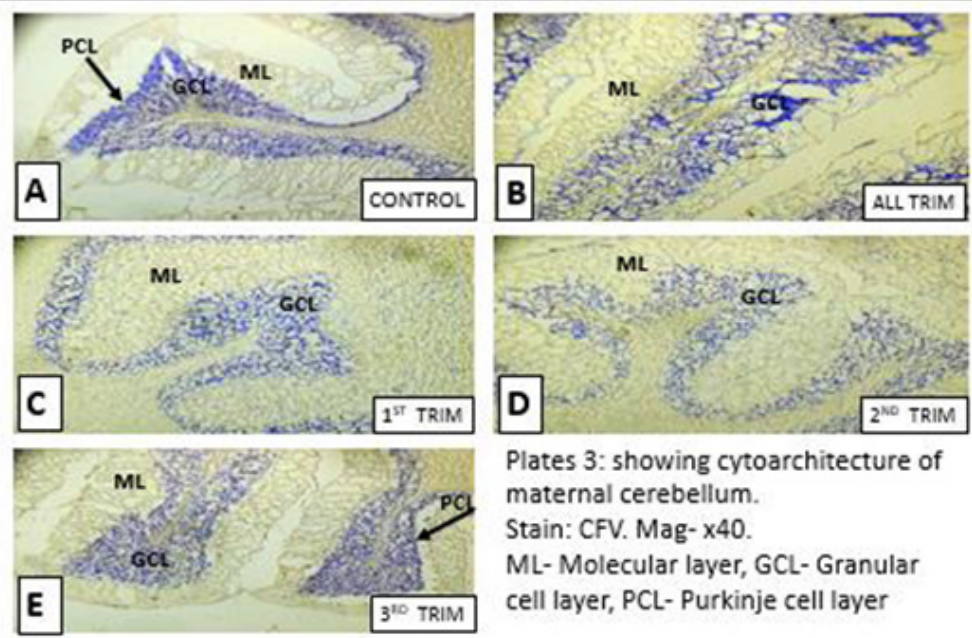

Plates 3: showing cytoarchitecture of maternal cerebellum.

Stain: CFV. Mag- x40.

ML- Molecular layer, GCL- Granular cell layer, PCL- Purkinje cell layer

Figure 4 Showing cytoarchitecture of maternal cerebellum. Stain, CFV. Mag- $\times 40$.

$\mathrm{ML}$, molecular layer; $\mathrm{GCL}$, granular cell layer; $\mathrm{PCL}$, purkinje cell layer

Citation: Peace GK Ufuoma EB, Jervas E. Histological studies on the effect of calabash chalk on the cerebellum of gestating Wistar rats. MOJ Anat Physiol. 2018;5(I):50-55. DOI: 10.15406/mojap.2018.05.00163 

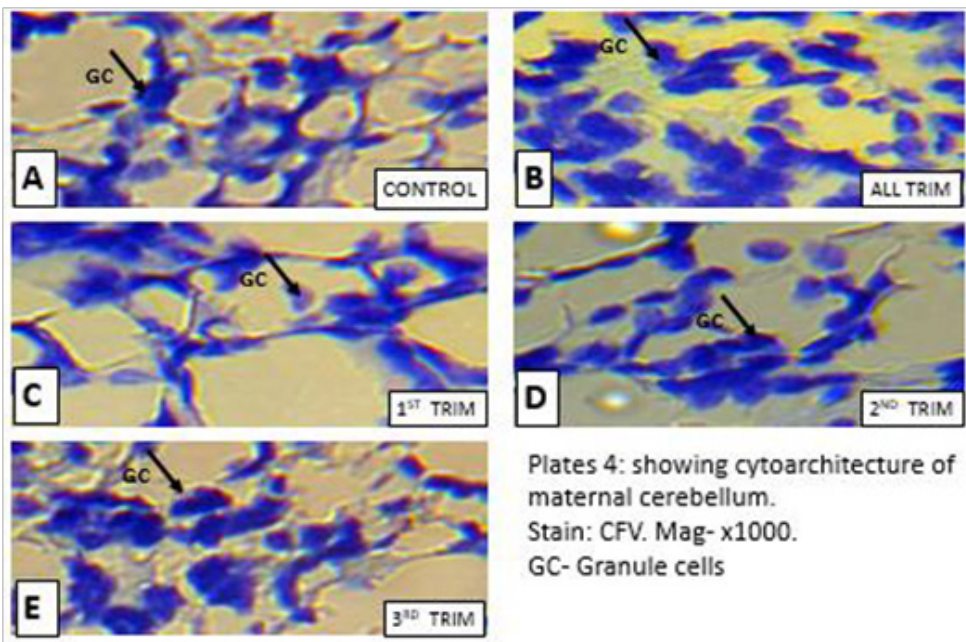

Plates 4 : showing cytoarchitecture of maternal cerebellum.

Stain: CFV. Mag- x1000.

GC- Granule cells

Figure 5 Showing cytoarchitecture of maternal cerebellum. Stain, CFV. Mag- $\times 1000$.

GC, granule cells
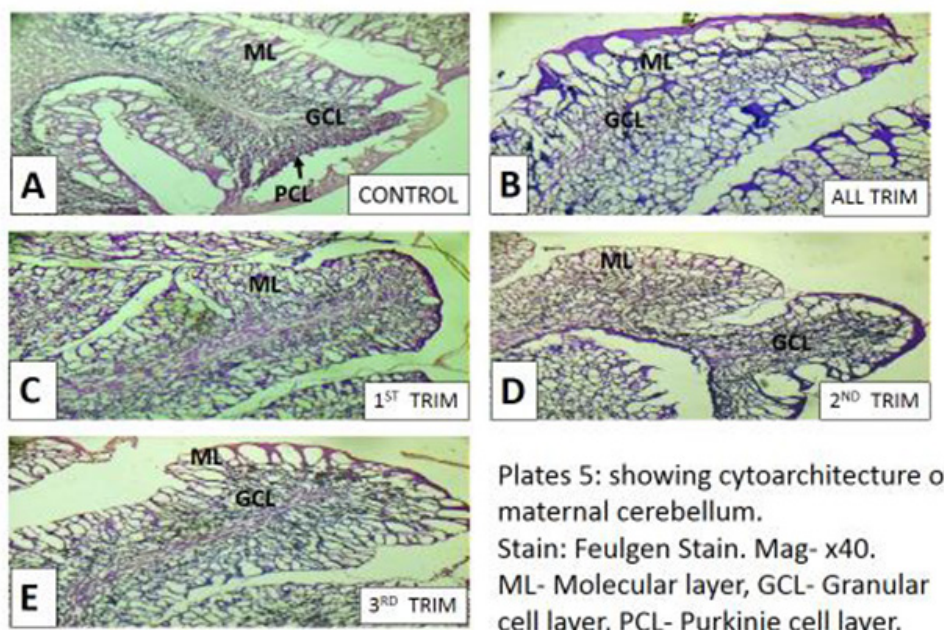

Plates 5: showing cytoarchitecture of maternal cerebellum.

Stain: Feulgen Stain. Mag- $x 40$.

ML- Molecular layer, GCL- Granular cell layer, PCL- Purkinje cell layer.

Figure 6 Showing cytoarchitecture of maternal cerebellum. Stain, Feulgen Stain. Mag- $\times 40$.

$\mathrm{ML}$, molecular layer; $\mathrm{GCL}$, granular cell layer; $\mathrm{PCL}$, purkinje cell layer
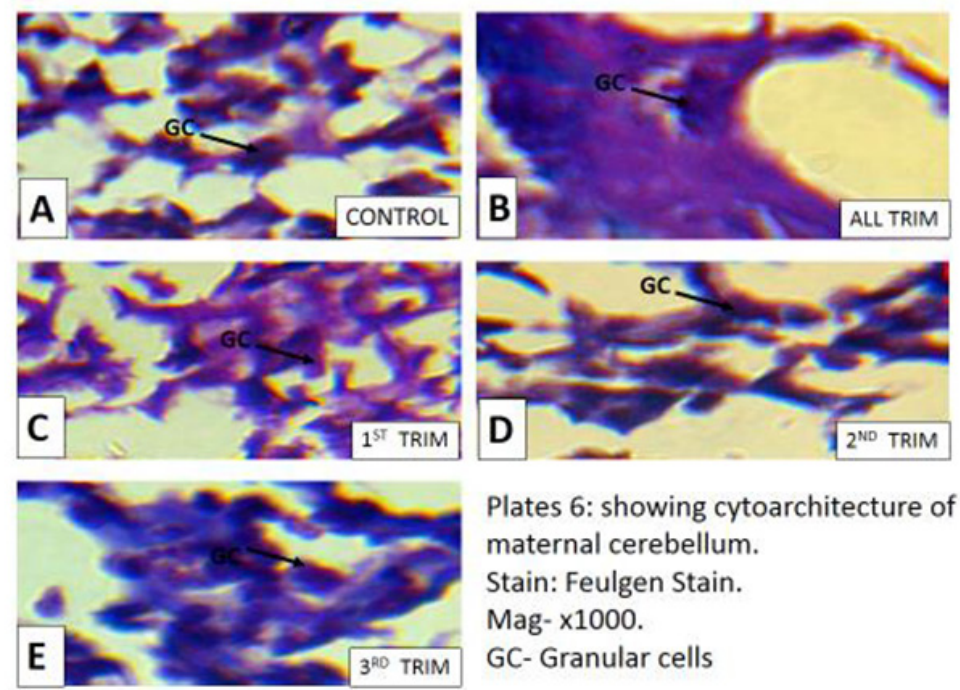

Plates 6: showing cytoarchitecture of maternal cerebellum.

Stain: Feulgen Stain.

Mag- x1000.

GC- Granular cells

Figure 7 Showing cytoarchitecture of maternal cerebellum. Stain, feulgen stain. Mag- $\times 1000$

GC, granular cells

Citation: Peace GK Ufuoma EB, Jervas E. Histological studies on the effect of calabash chalk on the cerebellum of gestating Wistar rats. MOJ Anat Physiol. 2018;5(I):50-55. DOI: 10.15406/mojap.2018.05.00163 


\section{Discussion}

Different adverse reports have been ascribed to calabash chalk's consumption. Higher cellular population, hypertrophied pyramidal cells, and vacuolation in the cerebral cortex, ${ }^{11}$ reduction in erythrocyte indices ${ }^{15}$ risk to the mental development of the developing unborn babies and breast feeding infants, ${ }^{16}$ liver damage, gastrointestinal alterations, ${ }^{13,20}$ and demineralization of the femur bone. ${ }^{21}$

During gestation there were no significant differences $(\mathrm{P}<0.05)$ that existed in body weight between control and the experimented groups. However, there were weekly body weight gains among all the groups as the experimented groups were exposed to the same $0.5 \mathrm{ml}$ aqueous solution of calabash chalk. This result indicates that the rats may have had the same baseline age, growth rate and pregnancy rate. Thus, the chalk may not have had effect on the body weight of the gestating rat. This indicates that administration of calabash chalk may not always affect the body weight of the maternal. This agrees with the work of ${ }^{11}$ which showed no differences in body weight gain by the dams between the control and the treated groups following an exposure to calabash chalk.

The histological analysis of the maternal cerebellum using haematoxylin and eosin, cresyl fast violet and feulgen staining techniques showed distortion of the external germinal layer (EGL), vacuolation of the Purkinje cells, changes in the cytoarchitecture of the cerebellar layers and hyperplasia of the granule cells in the treated groups of the maternal. These changes will lead to cerebellar dysfunction. This correlates with the work of ${ }^{11}$ which showed section of the cerebral cortex with a higher cellular population, hypertrophied pyramidal cells, and vacuolation in the treatment groups which indicated that calabash chalk may have anxiolytic effect especially at high dose in the light and dark field but not in the open field and can stimulate cellular changes in the maternal cerebral cortex. Ali and colleagues deduced that high consumption of yoyo cleanser bitters for long period of time will have a significant effect on the histology of the cerebellum of wistar rats which leads to hypertrophied granular layer of the cerebellum with a corresponding increase in granular cells. ${ }^{22}$ Lorton and Anderson in their study on quantitative histological examination and Golgi analysis of the cerebellum, revealed a number of alterations in the lead treated rats. ${ }^{23}$ Lead exposure resulted in a significant decrease in the molecular layer width (72\%). The granule cell density was depressed in the lead exposed rats, despite the observation that the granule cell layer width did not differ significantly. ${ }^{23}$ This agrees with the findings of our study since calash chalk contains above the recommended doses/levels of the aforementioned element/ compounds required for human consumption.

\section{Conclusion}

The components of the calabash chalk such as lead, arsenic, aluminum, and kaolin are known to cross the blood-brain barrier and to cause different effects in different parts of the brain. Neurons are not known to proliferate when traumatized; therefore the consumption of $0.5 \mathrm{ml}$ aqueous solution of calabash chalk containing $40 \mathrm{mg} / \mathrm{ml}$ during gestation should be discourage because it causes changes in the maternal cerebellar layers which could lead to cerebellar dysfunctions such as inability to maintain equilibrium or clumsy movement.

\section{Acknowledgements}

None.

\section{Conflict of interest}

Author declares that there is no conflict of interest.

\section{References}

1. Young SL, Wilson MJ, Miller D, et al. Toward a comprehensive approach to the collection and analysis of pica substances, with emphasis on geophagic materials. PloS One. 2008;3(9):e3147.

2. Myers T. Mosby's dictionary of medicine, nursing and health professions. Missouri: St. Loius, Mosby Elsevier; 2006.

3. Abrahams P. Human geophagy: a review of its distribution, causes, and implications. In: Skinner CW, Berger AR, editors. Geology and Health: Closing the Gap. London: Oxford University Press; 2003.

4. Abrahams PW, Davies TC, Solomon AO, et al. Human Geophagia, Calabash Chalk and Undongo: Mineral Element Nutritional Implications. PLoS One. 2013;8(1):e53304.

5. Gilardi JD, Duffey SS, Munn CA, et al. Biochemical functions of geophagy in parrots: Detoxification of dietary toxins and cytoprotective effects. $J$ Chem Ecol. 1999;25(4):897-922.

6. Al Rmalli SW, Jenkins RO, Watts MJ, et al. Risk of human exposure to arsenic and other toxic elements from geophagy: trace element analysis of baked clay using inductively coupled plasma mass spectrometry. Environ Health. 2010;9:79.

7. Abrahams PW, Follansbee MH, Hunt A, et al. Iron nutrition and possible lead toxicity: an appraisal of geophagy undertaken by pregnant women of UK Asian communities. Appl Geochem. 2006;21(1):98-108.

8. Middleton JD, Sikor. an unquantified hazard. BritMedJ. 1989;298:407-408.

9. Food Standards Agency. Calabash chalk: your questions answered. London; 2002.

10. Dean JR, Deary ME, Gbefa BK, et al. Characterisation and analysis of persistent organic pollutants and major, minor and trace elements in Calabash chalk. Chemosphere. 2004;57(1):21-25.

11. Ekong MB, Aniekan IP, Ekanem TB, et al. Calabash chalk's geophagy affects gestating rats' behavior and the histomorphology of the cerebral cortex. International J of Brain Sci. 2014. 8p.

12. Abrahams PW, Parsons JA. Geophagy in the tropics: a literature review. Geogr J. 1996;162(1):63-72.

13. Moses BE, Emma EJ, Christopher CM, et al. Effect of calabash chalk on the histomorphology of the gastro-oesophageal tract of growing wistar rats. Malays J Med Sci. 2012;19(1):30-35.

14. Kawai K, Saathoff E, Antelman G, et al. Geophagy (soil-eating) in relation to anemia and helminth infection among HIV-infected pregnant women in Tanzania. Am J Trop Med Hyg. 2009;80(1):36-43.

15. Akpantah AO, Ibok OS, Ekong MB, et al. The effect of calabash chalk on some hematological parameters in female adult Wistar rats. Turk $J$ Haematol. 2010;27(3):177-181.

16. Health Canada. Calabash chalk may pose health risk for pregnant and breastfeeding women. 2007.

17. Food Standards Agency. Calabash chalk warning. London, UK; 2003.

18. Commission Regulation. Commission Regulation (EC) No. 466/2001, Setting maximum levels for certain contaminants in foodstuffs. 2001.

19. Marcondes FK, Bianchi FJ, Tanno AP. Determination of the estrous cycle phases of rats: some helpful considerations. Braz $J$ Bio. 2002;62(4A):609-614. 
20. Ekong MB, Akpantah AO, Ibok OS, et al. Differentia effects of calabash chalk on the histology of liver of adult Wistar rats. The Internet Journal of Health. 2009;8(2).

21. Ekong MB, Ekanem TB, Sunday AO, et al. Evaluation of calabash chalk effect on femur bone morphometry mineralization in young Wistar rats: a pilot study. Int J Appl Basic Med Res. 2012;2(2):107-110.
22. Ali IM, Umar B, Uzokwe C, Umaru GJ, Muhammad MB, et al. (2014) The effect of Yoyo cleanser bitters on the cerebellum of adult male wistar rat. Sky Journal of Medicine and Medical Sciences. 2014;2(5):021-030.

23. Lorton D, Anderson WJ. The effects of postnatal lead toxicity on the development of cerebellum in rats. Neurobehav Toxicol Teratol. 1986;8(1):51-59. 